\title{
Digital health: the future of healthcare
}

\section{(1) Nihad Mešanović*, DElnur Smajić}

Public Health Institution University Clinical Center Tuzla, Tuzla, Bosnia and Herzegovina
RECEIVED:

October 21, 2018

ACCEPTED:

November 5, 2018

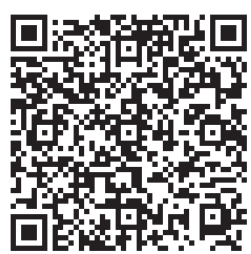

KEYWORDS: digital health, mHealth, e-cardiology.

CITATION: Cardiol Croat. 2018;13(11-12):461. | https://doi.org/10.15836/ccar2018.461

*ADDRESS FOR CORRESPONDENCE: Nihad Mešanović, JZU Univerzitetski klinički centar Tuzla, Trnovac bb, 75000 Tuzla, Bosnia and Herzegovina. / Phone: +38761152152 / E-mail: mesanovicmail@gmail.com

ORCID: Nihad Mešanović, https://orcid.org/0000-0003-1912-1155 • Elnur Smajić, https://orcid.org/0000-0003-0881-9443

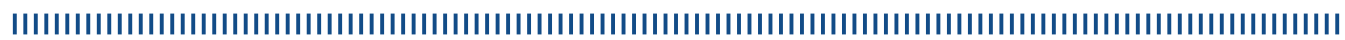

Digital health technologies have flooded the consumer marketplace in the past few years, focusing primarily on mobile health (mHealth) tools, including smartphone applications, wearables, and "smart" devices such as blood pressure devices, smart watches or digital weight scales. ${ }^{1}$ Digital health technologies tend to the potential to transform health care delivery, but most technology companies are targeting consumer products rather than developing digital tools for clinicians or to integrate those tools into clinical care. On the other hand, digital health tools provide the opportunity for more personalized care. Those that provide two-way communication between the health care provider and the patient can be individualized for the patient and provide a bit more of a human touch when you're interacting with both parties. Adoption of digital health technologies in medicine will change health care delivery from traditional hospital- or office-based visits to technologybased interactions that are virtual, on-demand and patient-centered. Integration of digital health tools into clinical practice also has the potential to improve patient outcomes and reduce costs in healthcare. Digital health companies from startups to the largest technology companies are eager to work with the health professionals and engineers because they recognize that the most effective way to develop new health technologies is to partner with the clinical enterprise. The overall goal is to partner with these companies, identify the problems and help design tools to solve those problems. In this paper, the past, present and future in digital health is presented, as well as how social media can change the health care with some real cases. 